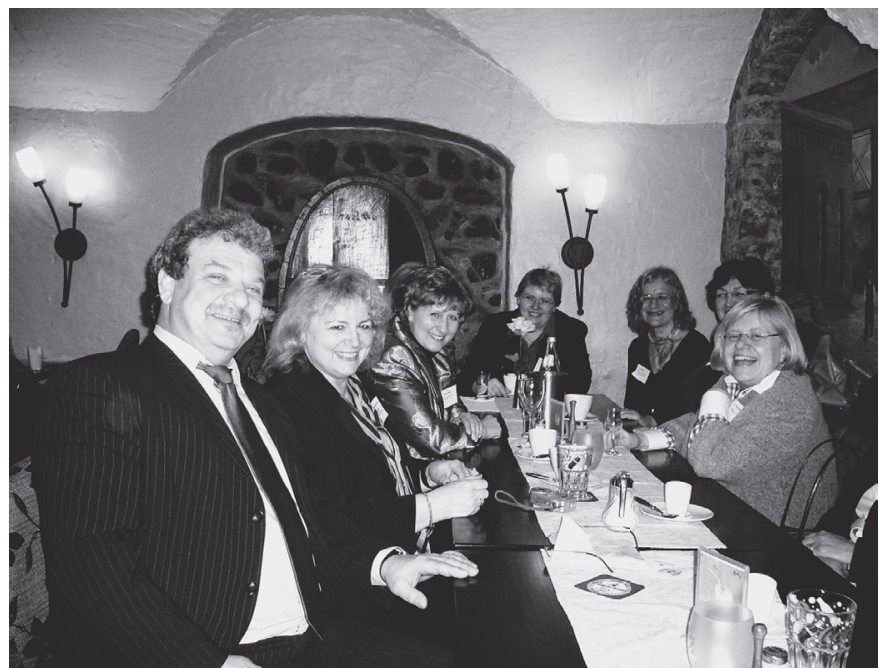

Böttger (Referatsleiterin MASGF), Annette Krause (Rechtsanwältin) und Ariane Thiele (Wirtschaftsministerium) mit den Themen Landesgleichstellungsgesetz, AGG, Arbeitsrecht und Existenzgründung durch Frauen, ergänzt um die Aspekte Coaching/frühzeitige Förderung durch Birgit Hendrischke (BTU Cottbus).

Zum anschließenden Empfang des Landesverbands begrüßte die Präsidentin des djb, Rechtsanwältin und Notarin Jutta Wagner, die Teilnehmerinnen und Gäste sehr herzlich $\varangle$ Empfang im Rahmen der Brandenburgischen Frauenwoche in Cottbus, v.I.n.r.: Frank Szymanski, Oberbürgermeister der Stadt Cottbus; Sigrun von Hasseln-Grindel, Schirmfrau der Frauenwoche Cottbus; Sabine Hiekel, Gleichstellungsbeauftragte der Stadt Cottbus; Ariane Thiele, Oberregierungsrätin; Karin Böttger, Referatsleiterin MASGF; Christel Henk, Rechtsanwältin, Schriftführerin des LV Brandenburg im djb; Dr. Ursula Bücker, Notarin, Stellv. Vorsitzende des LV Brandenburg im djb.

und erläuterte mit Beispielen aus Gesetzgebung und Rechtsprechung, wie sich die fachliche Arbeit des Verbandes auswirkt. Viele Frauen nutzten die Gelegenheit, in Einzelgesprächen mit den zahlreich vertretenen djb-Mitgliedern weitere Fragen zum Thema „Frau in Familie und Beruf“ zu erörtern. Den entspannten Abschluss des Tages genossen die djb-Frauen beim Abendessen mit dem Oberbürgermeister der Stadt Cottbus, Frank Szymanski, auf dessen Einladung. (Jutta Cremers/ Ramona Pisal)

\title{
Rezension: DAV-Ratgeber für Junge RechtsanwältInnen
}

\section{Euro für wirklich gutes Starterwissen!}

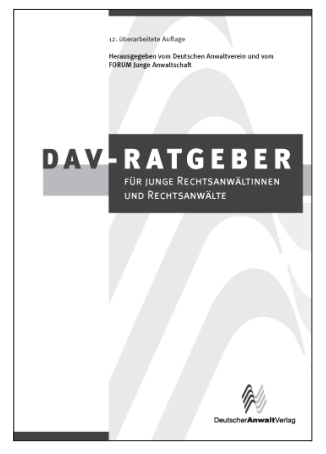

Der DAV-Ratgeber für junge Rechtsanwältinnen und Rechtsanwälte ist neu aufgelegt. Die überarbeitete 12 . Auflage bietet auf 790 Seiten praktische Antworten auf die wichtigsten Fragen beim Berufseinstieg. Unabhängig davon, ob die ersten Schritte in der Anwaltschaft im Angestelltenverhältnis oder in der Selbständigkeit gegangen werden: Der Ratgeber des Deutschen Anwaltvereins in Zusammenarbeit mit dem

FORUM Junge Anwaltschaft ist ein Standardwerk und bietet gebündeltes Wissen und Praktikertipps.

Die Themen sind weit gefasst: so werden zum Beispiel die Anwaltschaft im Allgemeinen mit Blick auf die Berufsethik und das anwaltliche Berufsrecht, die Rolle der Versorgungswerke und auch der mögliche Abschluss wichtiger Versicherungen dargestellt. Die Existenzgründung wird von der Planung und Finanzierung der eigenen Kanzlei bis hin zum Per- sonalmanagement erörtert; daneben werden Bewerbungsoptionen für den angestellten Anwaltsberuf sowie auch weitergehende empfehlenswerte Literatur für Einsteiger empfohlen. Darüber hinaus wird der heute zunehmend wichtigen Frage nach dem „Ob und Wie“ einer Spezialisierung viel Bedeutung beigemessen: Umfangreich werden auf etwa 150 Seiten neben nahezu allen Fachanwaltschaften auch weitere Tätigkeitsbereiche von erfahrenen Praktikern „vorgestellt“ und ein erstes Bild der Anwaltstätigkeit in einer dieser Spezialisierungen gezeigt.

Insbesondere mit seiner formularbuchartigen Darstellung z.B. eines Kanzleigründungsplans und zahlreichen Musterverträgen bietet der Ratgeber eine konkrete Hilfestellung, die nicht nur theoretisch fundiert ist, sondern der Leserin auch tatsächlich einen praktisch umsetzbaren Rat eines erfahrenen Kollegen an die Hand gibt.

Der Ratgeber für junge Rechtsanwältinnen und Rechtsanwälte ist gegen eine Schutzgebühr von 5 Euro beim Deutschen Anwaltverein zu beziehen. (Christiane A. Lang, Rechtsanwältin, Berlin) 